\title{
Современные подходы в терапии NK/T-клеточных лимфом
}

\author{
Национальный институт рака, Киев \\ Получено 3.07.2020 \\ Принято в печать 21.07.2020 \\ DOI: 10.32471/clinicaloncology.2663-466X.37-1.27147
}

\begin{abstract}
Экстранодальные NK/T-клеточные лимфомы остаются одной из наиболее сложных нозологий в онкогематологии. Применение стандартных схем химиотерапии, таких как СНОР или СНОР-подобные схемы, недостаточно эффективно. В настоящее время продолжается поиск новых препаратов и схем для лечения больных с экстранодальной NK/T-клеточной лимфомой, которые бы улучшили результаты терапии данной категории больных.
\end{abstract}

Ключевые слова: NK/T-клеточная лимфома; химиотерапия; лучевая терапия.

Злокачественные заболевания лимфоидной ткани, несмотря на постоянное внедрение новых технологий диагностики, программ лечения и новейших химиопрепаратов, остаются важной проблемой как в Украине, так и в мире. Ежегодно уровень заболеваемости лимфомами повышается и за последние 20 лет увеличился практически вдвое.

Несмотря на повышение уровня заболеваемости, в последние годы произошел большой прогресс в диагностике и лечении лимфом, что привело к улучшению выживаемости больных с этой патологией, но уровень смертности остается достаточно высоким. Одними из наиболее проблемных и сложных вариантов неходжкинских лимфом являются NK/T-клеточные опухоли, которые встречаются редко и характеризуются клинико-морфологическим разнообразием.

Согласно классификации ВОЗ (2016) новообразований из зрелых Т-лимфоцитов, NK-клеток, гистиоцитов и дендритных клеток к NK/T-клеточным опухолям относят: хроническиий лимфопролиферативный процесс из NKклеток, агрессивный NK-клеточный лейкоз, экстранодальную NK/T-клеточную лимфому назального типа $[1,2]$.

Экстранодальная NK/T-клеточная лимфома - редкое лимфопролиферативное заболевание, характеризующееся преимущественно экстранодальной локализацией, агрессивным течением и низкой эффективностью стандартной химиотерапии [3, 4]

Диагноз экстранодальной NK/T-клеточной лимфомы устанавливается на основании гистологического и иммуногистохимического исследований биоптата лимфатичекого узла или патологического очага. Дополнительные обследования включают общий анализ крови, биохимическое исследование крови с обязательным определением уровня лактатдегидрогеназы, исследование костного мозга, компьютерную томографию или позитронно-эмиссионную томографию шеи, органов грудной, брюшной полостей, малого таза.

S.J. Kim и соавторы провели ретроспективное исследование для определения прогностических факторов при экстранодальной NK/T-клеточной лимфоме. В исследование было включено 527 пациентов из 38 лечебных учреждений в 11 странах мира. Анализ показал, что возраст старше 60 лет, III или IV стадия заболевания, вовлечение отдаленных лимфатических узлов и неназальный тип патологии влияли на общую и безрецидивную выживаемость. На основе этих факторов был разработан прогностический индекс (PINK), в котором пациенты были стратифицированы в группу низкого риска (без факторов риска), промежуточного риска (1 фактор риска) или высокого риска (2 или больше факторов риска), 3-летняя общая выживаемость зависела от групп риска и составила 81 , 62 и $25 \%$ соответственно. Также авторами была изучена про- гностическая роль вируса Эпштейна - Барр. У 328 пациентов исследуемой группы вирусный титр ДНК был независимым прогностическим фактором общей выживаемости. Эти данные были добавлены к прогностической шкале PINK в качестве основы для другого прогностического индекса (PINK-E), в соответствии с которым пациентов также разделяют на 3 прогностические группы: низкого (отсутствие или 1 фактор риска), промежуточного (2 фактора риска) и высокого риска (3 и больше факторов риска) и показали разную общую выживаемость $(81,55$ и $28 \%$ соответственно). В результате исследования авторы сделали выводы, что PINK и PINK-E это новые прогностические модели, которые могут использоваться для разработки риск-адаптированных терапевтических подходов для пациентов с экстранодальной NK/T-клеточной лимфомой, с использованием терапии, которая не содержит антрациклины [5].

Экстранодальная NK/T-клеточная лимфома характеризуется низким ответом на стандартную химиотерапию. Многие годы идет поиск новых эффективных методов лечения данной патологии. М. Yamaguchi и соавторы провели исследование II фазы по изучению эффективности и токсичности режима SMILE (дексаметазон, метотрексат, ифосфамид, $\mathrm{L}-$-аспарагиназа и этопозид). В исследование были включены 38 пациентов с IV стадией патологического процесса, peцидивирующим или рефрактерным течением, статусом по шкале Восточной объединенной группы онкологов (Eastern Cooperative Oncology Group - ECOG) 0-2. Средний возраст пациентов составил 47 лет (диапазон 16-67 лет). IV стадия заболевания диагностирована у 20 пациентов, первый рецидив был отмечен у 14 пациентов и первично-рефрактерное течение - у 4 больных. В качестве протокольного лечения применяли 2 курса химиотерапии по схеме SMILE. Общий и полный ответ на терапию составили 79 и $45 \%$ соответственно. Из 28 пациентов, завершивших лечение, 19 выполнена трансплантация гемопоэтических стволовых клеток. Общая выживаемость в течение 1 года составила 55\%. Уровень нейтропении 4-й степени наблюдали у $92 \%$ пациентов. Наиболее распространенным негематологическим осложнением 3-й или 4-й степени была инфекция(61\%). Авторы сделали вывод, что курс полихимиотерапии по схеме SMILE является эффективным лечением NK/T-клеточной лимфомы у пациентов с впервые установленной IV стадией заболевания, а также при рецидиве или рефрактерном течении [6].

Во французском проспективном исследовании II фазы изучали эффективность и токсичность схемы терапии, также включавшей L-аспарагиназу. В исследование включены 11 пациентов с рецидивирующим и $8-$ с рефрактерным течением заболевания, лечившихся в 13 центрах. Средний 
возраст пациентов составлял 60 лет (диапазон 45-77 лет). На момент включения у 7 пациентов была установлена стадия IE, у 5 - IIE (4 пациента с нодальным вовлечением) и у 7 IV стадия заболевания (с поражением печени у 2 пациентов, костного мозга у 3 пациентов, мышц у 2 пациентов и кожи у 2 пациентов). Использовался режим терапии AspaMetDex (L-аспарагиназа, метотрексат, дексаметазон), который был эффективен у 14 пациентов после 3 курсов терапии. У 11 пациентов (61\%) отмечали полную ремиссию, и только у 4 из них развился рецидив заболевания. Медиана общей выживаемости составила 12 мес, медиана продолжительности ответа - 12 мес. Основными нежелательными явлениями были гепатит, цитопения и аллергия. Таким образом, авторы сделали выводы, что лечение на основе L-аспарагиназы следует рассматривать как эффективную опцию salvage-терапии, особенно у пациентов с распространенным заболеванием [7].

Новые схемы лечения на основе L-аспарагиназы, такие как GELOX (гемцитабин, оксалиплатин и L-аспарагиназа) и P-GEMOX (гемцитабин, оксалиплатин и пегаспаргиназа), показали многообещающие результаты при применении у больных NK/T-лимфомой на стадии IE/IIE. J.H. Wang и соавторы провели ретроспективный анализ эффективности и безопасности схемы P-GEMOX. В исследование было включено 117 пациентов с впервые установленным диагнозом или рецидивирующим/рефрактерным течением заболевания. Лечение включало от 2 до 8 курсов P-GEMOX: гемцитабин

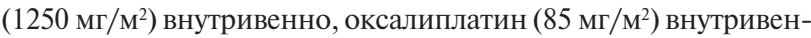
но, пегаспаргаза (2500 ME/M²) внутримышечно в 1-й день и затем каждые 2 нед или гемцитабин (1000 мг/м²) внутривенно

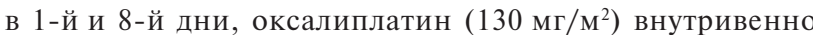
и пегаспаргаза (2500 ME/м2) внутримышечно в 1-й день и затем каждые 3 нед. Общий ответ на терапию составил $88,8 \%$, а эффективность терапии была аналогичной для больных с впервые установленным диагнозом, а также при рецидиве и рефрактерном течении. Медиана наблюдения составила 17 мес, общая 3-летняя выживаемость и беспрогрессивная выживаемость составила 72,7 и $57,8 \%$ соответственно. Многофакторный анализ показал, что полный ответ после завершения лечения является наиболее значимым фактором, влияющим на выживаемость. Таким образом, было установлено, что режим P-GEMOX является эффективным и хорошо переносимым методом лечения для пациентов с экстранодальной NK/T-клеточной лимфомой [8].

S. Qi и соавторы проанализировали результаты лечения 43 пациентов с экстранодальной NK/T-клеточной лимфомой, которые получали лечение с 1996 до 2014 г., в том числе $10(23 \%)$ азиатского происхождения и $33(76 \%)$ неазиатского. 19 из 26 (73\%) пациентов с ранними стадиями получали химиотерапию по схеме СНОР или СНОР-подобные с последующей лучевой терапией. 14 из 17 (82\%) пациентов с распространенными стадиями получали модифицированный курс химиотерапии по схеме SMILE. Количество полных ответов было значительно больше в группе пациентов, которые получали модифицированные курсы SMILE по сравнению с группой больных, которые получали СНОР или СНОР-подобные режимы (80 vs 30\%, $\mathrm{p}=0,015$ ). 2-летняя общая выживаемость и выживаемость без прогрессирования составили 60 и $40 \%$ соответственно. У пациентов с ранними стадиями заболевания отмечали значительно более высокий уровень 2-летней общей выживаемости (87 vs 21\%) и выживаемости без прогрессирования (56 vs 18\%) по сравнению с распространенными стадиями $(\mathrm{p}<0,001)$. Этническая принадлежность пациентов не влияла на исход терапии. Экстранодальная NK/T-клеточная лимфома назального типа у больных в неазиатских странах характеризовались сходными признаками и результатами терапии по сравнению с пациентами азиатского происхождения. Большинство больных на ранних стадиях достигли длительной ремиссии. Однако у пациентов с распространенными стадиями отмечали высокие показатели прогрессии заболевания и смертности [9].

Для определения более эффективного лечения экстранодальной NK/T-клеточной лимфомы M. Yamaguchi и соавторы провели исследование эффективности параллельной химиолучевой терапии. Лечение включало одновременную лучевую терапию (50 Гр) и 3 курса дексаметазона, этопозида, ифосфамида и карбоплатина (схема DeVIC: дексаметазон 40 мг/сут внутривенно в дни 1-3, этопозид 67 мг/м² внутривенно за 2 ч в 1-3-й дни, ифосфамид 1,0 г/м ${ }^{2}$ внутривенно за 3 ч в $1-3$-й дни и карбоплатин

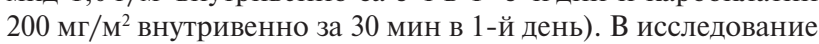
были включены пациенты с впервые установленным диагнозом, IE или IIE стадией заболевания, с вовлечением шейных лимфатических узлов и оценкой по шкале ECOG от 0 до 2. Главной целью этого исследования II фазы было определение общей 2-летней выживаемости у пациентов, которые получали терапию согласно рекомендованным дозам. 27 пациентов получали препараты в рекомендованных дозах, средний возраст составил 56 лет (диапазон 21-68 лет), из которых мужчин -17, женщин - 10. IE стадия установлена у 18 пациентов, IIE у 9; симптомы отмечали у 10 пациентов; повышенная лактатдегидрогеназа в сыворотке крови зарегистрирована у 5 и ЕCOG 2 - у 2 больных. Медиана наблюдения составила 32 мес. Из 26 оцениваемых пациентов 20 (77\%) достигли полного ответа и 1 - частичного ответа. Общий ответ на лечение составил $81 \%$. 2-летняя общая выживаемость $-78 \%$, при этом при применении только лучевой терапии уровень общей выживаемости достиг только 45\%. На основании полученных результатов был сделан вывод о том, что химиолучевая терапия является более эффективным методом лечения пациентов с экстранодальной NK/T-клеточной лимфомой по сравнению с лучевой терапией. Наиболее распространенной негематологической токсичностью 3-й степени был мукозит, связанный с лучевой терапией (30\%). Смертельных случаев, связанных с лечением, не было отмечено. В результате исследования был сделан вывод, что параллельная химиолучевая терапия является безопасным и эффективным методом лечения экстранодальной NK/T-клеточной лимфомы и требует дальнейшего изучения [10].

Изучению эффективности применения параллельной химиолучевой терапии при экстранодальной NK/Tклеточной лимфоме было посвящено еще одно исследование. S.J. Kim и соавторы провели исследование II фазы, в котором 30 пациентов с назальной экстранодальной NK/T-клеточной лимфомой с впервые установленным диагнозом на стадиях IE и IIE получали химиолучевую терапию в параллельном режиме (то есть облучение от 40 до 52,8 Гр и цисплатин

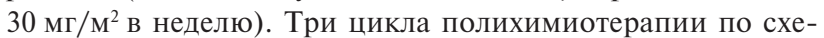
ме VIPD (этопозид 100 мг/м² в 1-3-й дни, ифосфамид

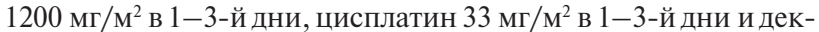
саметазон 40 мг в 1-4-й дни) были запланированы после завершения этапа параллельной химиолучевой терапии. Все пациенты завершили этап параллельной химиолучевой терапии. Общий ответ на терапию составил $100 \%$, из которых у $22(73,3 \%)$ были полные ответы и у 8 - частичные ответы. 26 из 30 пациентов завершили запланированные 3 цикла VIPD. Общий ответ и полный ответ на лечение составили 83,3 и 80,0\% соответственно. 3-летняя беспрогрессивная и общая выживаемость составила 85,19 и $86,28 \%$ соответственно [11].

X.W. Вi и соавторы изучали эффективность лечения пациентов пожилого возраста с экстранодальной NK/Tклеточной лимфомой, у которых сравнивали эффективность проведения только химиотерапии и лучевой терапии с/без химиотерапии. Ретроспективно были проанализированы данные 63 пожилых больных с впервые диагностированной экстранодальной NK/T-клеточной лимфомой. Среди пациентов с I-II стадией заболевания 58,3\% получали лучевую 
терапию \pm химиотерапию, а 41,7\% получали только химиотерапию. По сравнению с группой пациентов, которые получали только химиотерапию, в группе больных, которые получали лучевую терапию \pm химиотерапию был достигнут более высокий показатель общего ответа на лечение (100 против $57,1 \%, \mathrm{p}<0,001)$ и существенно более длительная 5-летняя общая выживаемость $(55,3$ против $18,0 \%, \mathrm{p}<0,001)$ у пациентов c I-II стадией заболевания. По сравнению с другими химиотерапевтическими режимами пегаспаргиназа + гемцитабин и оксалиплатин $(\mathrm{PGEMOX}) / \mathrm{L}-$ аспарагиназа + гемцитабин и оксалиплатин (GELOX) были связаны со значительно более высоким общим ответом $(92,9$ против $51,6 \%, \mathrm{p}=0,009)$ и значительно лучшей 5-летней общей выживаемостью (78,6 против $23,9 \%, \mathrm{p}=0,010)$ у пациентов с I-II стадией заболевания. У 9 пациентов со стадией I-II болезни, которые получали PGEMOX/GELOX с последующей лучевой терапией, отмечали более высокие показатели 5-летней общей выживаемости

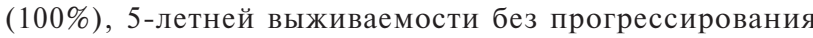
$(85,7 \%)$, по сравнению с пациентами, получающими другие режимы, за которыми следовала лучевая терапия. В результате исследования был сделан вывод, что лучевая терапия играет важную роль для пациентов пожилого возраста с ранней стадией экстранодальной NK/T-клеточной лимфомой, а режим PGEMOX/GELOX превосходит другие режимы. Таким образом, комбинация PGEMOX + лучевая терапия и GELOX + лучевая терапия может быть перспективным вариантом лечения для пациентов пожилого возраста [12].

С целью улучшения результатов лечения экстранодальной NK/T-клеточной лимфомы изучалось также влияние новых препаратов, в частности анти-PD1-антитела пембролизумаба. $\mathrm{Li}$ Xin и соавторы проанализировали лечение 7 пациентов с рефрактерным/рецидивирующим течением экстранодальной NK/T-клеточной лимфомы. Все пациенты получили по меньшей мере 2 предшествующих курса химиотерапии. Пембролизумаб в дозе 100 мг вводили каждые 3 нед. Средний возраст пациентов составил 47 лет (от 17 до 61 лет), оценка по шкале ECOG 1-2, среднее количество предшествующих режимов лечения составляло 4 (3-10). Среднее количество циклов пембролизумаба - 4 (2-18). Общий ответ на терапию составил $57,1 \%$, причем полный ответ наблюдали у $2(28,6 \%)$ пациентов и частичный ответ также у $2(28,6 \%)$ больных. Продолжительность ответа, безрецидивная выживаемость и общая выживаемость 7 пациентов составили 4,1; 4,8 и 5,0 мес соответственно [13].

Таким образом, курсы полихимиотерапии на основе L-аспаргиназы на сегодняшний день являются самыми эффективными, однако уровень выживаемости пациентов с данным видом лимфомы, особенно при поздних стадиях, остается низким. Также следует отметить, что химиотерапия на основе L-аспарагиназы в сочетании с лучевой терапией более эффективна при лечении больных с экстранодальной NK/Tклеточной лимфомой. Пациенты, которые получали этот вид лечения, показали значительно более высокую эффективность терапии и более пролонгированную выживаемость.

Продолжается поиск новых препаратов для лечения больных с экстранодальной NK/T-клеточной лимфомой, которые бы улучшили результаты терапии данной категории больных.

\section{СПИСОК ИСПОЛЬЗОВАННОЙ ЛИТЕРАТУРЫ}

1. Swerdlow, S. H., Campo, E., Pileri, S. A., Harris, N. L., Stein, H., Siebert, R., ... Jaffe, E. S. (2016). The 2016 revision of the World Health Organization classification of lymphoid neoplasms. Blood 127(20), 2375-2390 doi: 10.1182/blood-2016-01-643569.

2. Глузман, Д. Ф., Скляренко, Л. М., Иванивская, Т. С., Коваль, С. В., Украинская, Н. И., Полищук, А. С., ... Завелевич, М.П. (2016). Классификация ВОЗ новообразований из зрелыхТ-лимфоцитов, ЕК-клеток, гистиоцитов и дендритных клеток (пересмотр 2016 г.). Онкология, 19(2),92-96.

3. Swerdlow, S. H., Campo, E., Harris, N. L., Jaffe, E. S., Pileri, S. A., Stein, H., \& Thiele, J. (2008). WHO classification of tumor of haemato poietic and lymphoid tissues. Lyon: IARC.
4. Vose, J., Armitage, J., \& Weisenburger, D. (2008). International peripheral T-cell and natural killer/T-cell lymphoma study: pathology findings and clinical outcomes. Journal of Clinical Oncology, 26(25), 4124-4130. doi: 10.1200/JCO.2008.16.4558.

5. Kim, S. J., Yoon, D. H., Jaccard, A., Lim, S. T., Hong, H., Park, Y., ..., Kim, W. S. (2016). A prognostic index for natural killer cell lymphoma after non-anthracyclinebased treatment: a multicentre, retrospective analysis. Lancet Oncology, 17(3), 389-400. doi: 10.1016/S1470-2045(15)00533-1.

6. Yamaguchi, M., Kwong, Y. L., Kim, W. S., Maeda, Y., Hashimoto, C., Suh, C., Suzuki, R. (2011). Phase II study of SMILE chemotherapy for newly diagnosed stage IV, relapsed, or refractory extranodal natural killer (NK)/T-cell lymphoma, nasal type: the NK-Cell Tumor Study Group study. Journal of Clinical Oncology, 29(33), 4410-4416. doi: $10.1200 / J C 0.2011 .35 .6287$.

7. Jaccard, A., Gachard, N., Marin, B., Rogez, S., Audrain, M., Suarez, F., ... Hermine, O. (2011). Efficacy of L-asparaginase with methotrexate and dexamethasone (AspaMetDex regimen) in patients with refractory or relapsing extranodal NK/T-cell lymphoma, a phase 2 study. Blood, 117(6), 1834-1839. doi: 10.1182/blood-2010-09-307454

8. Wang, J. H., Wang, H., Wang, Y. J., Xia, Z. J., Huang, H. Q., Jiang, W. Q., \& Lu, $Y$. (2016). Analysis of the efficacy and safety of a combined gemcitabine, oxaliplatin and pegaspargase regimen for NK/T-cell lymphoma. Oncotarget, 7(23), 35412-3522. doi: 10.18632/oncotarget.8643

9. Qi, S., Yahalom, J., Hsu, M., Chelius, M., Lunning, M., Moskowitz, A., \& Horwitz, S. (2016). Encouraging experience in the treatment of nasal type extra-nodal NK/T-cell lymphoma in a non-Asian population. Leukemia \& Lymphoma, 57(11), 2575-2583. doi: 10.1080/10428194.2016.1180689.

10. Yamaguchi, M., Tobinai, K., Oguchi, M., Ishizuka, N., Kobayashi, Y., Isobe, Y., , Oshimi, K. (2009). Phase I/II study of concurrent chemoradiotherapy for localized nasal natural killer/T-cell lymphoma: Japan Clinical Oncology Group Study JCOG0211. Journal of Clinical Oncology, 27(33), 5594-5600. doi: 10.1200/JCO.2009.23.8295.

11. Kim, S. J., Kim, K., Kim, B. S., Kim, C. Y., Suh, C., Huh, J., ... Kim, W. S. (2009). Phase II trial of concurrent radiation and weekly cisplatin followed by VIPD chemotherapy in newly diagnosed, stage IE to IIE, nasal, extranodal NK/T-Cell Lymphoma: Consortium for Improving Survival of Lymphoma study. Journal of Clinical Oncology, 27(35), 6027-6032. doi: 10.1200/JCO.2009.23.8592.

12. Bi, X. W., Xia, Y., Zhang, W. W., Sun, P., Liu, P. P., Wang, Y., ... Li, Z. M. (2015). Radiotherapy and PGEMOX/GELOX regimen improved prognosis in elderly patients with early-stage extranodal NK/T-cell lymphoma. Annals of Hematology, 94(9), 1525-1533. doi: 10.1007/s00277-015-2395-y

13. Xin, Li, Yasong, Cheng, Mingzhi, Zhang, Jiaqin, Yan, Ling, Li, Xiaorui, Fu, Ken, H. Young (2018). Activity of pembrolizumab in relapsed/refractory NK/T-cell lymphoma. Journal of Hematology \& Oncology, 11, 15. doi: 10.1186/s13045-018-0559-7.

\section{Сучасні підходи до терапії NK/T-клітинних лімфом}

\section{Крячок І.А., Алексик О.М., Титоренко І.Б., Філоненко К.С.} Національний інститут раку, Київ

Резюме. Екстранодальні NK/T-клітинні лімфоми залишаються однією з найбільш складних нозологій в онкогематології. Застосування стандартних схем хіміотерапії, таких як СНОР або СНОР-подібні схеми, недостатньо ефективні. На даний час триває пошук нових препаратів і схем для лікування хворих з екстранодальною NK/T-клітинною лімфомою, які б поліпшили результати терапії даної категорії хворих.

Ключові слова: NK/T-клітинна лімфома; хіміотерапія; променева терапія.

\section{Modern approaches to the treatment of the extranodal NK/T-cell lymphoma}

\section{I.A. Kriachok, O.M. Aleksyk, I.B. Titorenko, K.S. Filonenko}

National Cancer Institute, Kyiv

Summary. Extranodal NK/T-cell lymphomas remain to stay of the most difficult diseases in hematology. Treatment with standard regimens, such as $\mathrm{CHOP}$ or CHOP-like schemas, are insufficient. Nowadays continues the search of new drugs and regimens for treatment of extranodal NK/T-cell lymphoma, which can improve treatment results in this patients' setting.

Key words: NK/T-cell lymphoma; chemotherapy; radiation therapy.

Адрес

Алексик Елена Михайловна

03022, Киев, ул. Ломоносова, 33/43

Национальный институт рака

E-mail:aleksik@bigmir.net 